\begin{tabular}{lcl}
\hline Bentham OPEN & Open Medicine Journal \\
CrossMark & Content list available at: www.benthamopen.com/MEDJ/ & $\begin{array}{l}\text { Open } \\
\text { Medicine } \\
\text { lournal }\end{array}$ \\
\hline
\end{tabular}

RESEARCH ARTICLE

\title{
Contemporary Mitral Valve Surgery for Septuagenarians and Octogenarians
}

\author{
Yi-Wen B. Liao, Tom K.M. Wang*, Sophie Harmos, Tharumenthiran Ramanathan and Peter \\ Ruygrok
}

Green Lane Cardiovascular Service, Auckland City Hospital, Auckland, New Zealand

Received: December 17, 2016

Revised: January 12, 2017

Accepted: January 20, 2017

\section{Abstract:}

Background:

The increasing prevalence of degenerative and functional mitral valve disease as the population ages alongside introduction of percutaneous mitral valve interventions mandates revision of outcomes of mitral valve surgery (MVS) in elderly and high risk patients. We compared the characteristics and outcomes of octogenarians and septuagenarians undergoing MVS.

\section{Methods:}

All patients over 70 years of age having isolated MVS at Auckland City Hospital during 2005-2012 were studied and divided into $70-79$ and $>80$ years age-groups for analysis.

\section{Results:}

There were 20 octogenarians and 81 septuagenarians studied. Apart from median age $(82.0$ vs. 74.0 years, $\mathrm{P}<0.001)$ and previous stroke $(15.0 \%$ vs. $1.2 \%, \mathrm{P}=0.024)$ respectively, there were no significant differences in pre-operative characteristics. Octogenarians however had significantly higher median EuroSCORE (4.5\% vs. 3.4\%, $\mathrm{P}=0.010)$ and STS Score (5.6 vs. 2.8\%, $\mathrm{P}=0.002)$. Despite this, octogenarians had numerically but not statistically significantly less operative mortality $(0.0 \% v s .7 .4 \%, \mathrm{P}=0.340)$. One, three and five-year survivals were $100.0 \%, 80.0 \%$ and $70.0 \%$ for octogenarians and $91.4 \%, 86.4 \%$ and $73.8 \%$ septuagenarians. There was also no difference in composite and individual post-operative complications including stroke ( $\mathrm{P}=0.358-1.000)$. The only independent predictor of operative mortality was cardiopulmonary bypass time odds ratio $1.02,95 \%$ confidence interval $1.00-1.04, \mathrm{P}=0.044$.

\section{Conclusion:}

Although octogenarians were older with higher risk scores, they did not have increased mortality and morbidity from MVS. MVS remains a safe procedure in selected octogenarians, and other factors beyond age and risk scores such as frailty would be important in deciding the modality of mitral valve intervention in elderly patients.

Keywords: Mitral valve, Cardiac surgery, Mitral valve repair, Mitral valve replacement, Geriatrics, Risk models.

\section{INTRODUCTION}

The world's first successful heart valve surgery was performed in 1923 on a 12 year-old girl with rheumatic mitral stenosis, and twenty years later, John Gibbon performed the first successful open heart surgery using cardiopulmonary bypass, often considered the most important advancement in heart valve surgery [1, 2]. Further refinements of surgical techniques, recommended for treating severe symptomatic valvular heart disease, have since been developed to meet

\footnotetext{
* Address correspondence to this author at the Auckland city hospital, Grafton road, Auckland 1023, New Zealand; Tel: +6493670000; E-mail: twang@adhb.govt.nz
} 
demands of the increasing prevalence of degenerative and functional valve disease for the aging population [3 - 5]. Mitral valve disease is common at over $10 \%$ in those over 75 years of age $[6,7]$. Age however is an established risk factor for cardiac surgery, and part of all conventional mortality risk models to help select favourable surgical candidates [8 - 10]. Due to the perceived high risk, many of these elderly patients remain untreated compared to their younger cohort $[6,7]$. The decision for intervention has also recently become more complex due to the introduction of percutaneous mitral valve techniques such as the mitraclip [11]. Reviewing the outcomes of mitral valve surgery (MVS) in high risk groups such as the elderly is therefore of great importance to guide clinical practice. The aim of this study is to review and compare the characteristics and outcomes of octogenarians and septuagenarians undergoing MVS.

\section{MATERIALS AND METHODS}

All patients over the age of 70 years undergoing isolated MVS at Auckland City Hospital during the period 2005-2012 were included, and grouped into 70-79 and >80 years of age for analysis. Study participants were identified retrospectively from the hospital's cardiothoracic surgical unit database. Baseline characteristics, operative variables and post-operative outcomes were retrieved from the hospital's electronic clinical records, with ethics approval attained before the study commencement from the Auckland District Health Board Research Office.

For the variables included in the study, angina class was defined according to the Canadian Cardiovascular Society grading and dyspnea class by the New York Heart Association. Other baseline characteristics followed the definitions of EuroSCORE II parameters [9]. EuroSCORE [8], EuroSCORE II [9] and Society of Thoracic Surgeon's (STS) Scores [10] were calculated for all patients.

Mortality data was obtained from the "Births, Deaths and Marriages registers" of New Zealand up till December 2015. Operative mortality was defined as in-hospital deaths or deaths within 30 days of surgery. The five post-operative complications (stroke, renal failure, ventilation $>24 \mathrm{hrs}$, mediastinitis and return to theatre) and their composite were defined as per the STS database [10]. Survival rates at one, three and five-years were recorded.

Median (lower-upper quartile) and percentages (frequency) are used to present continuous and categorical variables respectively. Univariate analysis was performed using Mann- Whitney U Test and Fisher's Exact Test for continuous and categorical variables respectively. Longitudinal survival was analysed by Kaplan-Meier curves and log-rank (Mantel-Cox) test. Area under the receiver operative characteristics curves (c-statistics) with 95\% confidence intervals $(95 \% \mathrm{CI})$ were used to assess the discriminative ability of risk scores. Variables with $\mathrm{P}<0.20$ in univariate analysis were selected for multivariate analysis to identify independent predictors of various surgical outcomes. Logistic regression and Cox Proportional Hazards Regression were used for cross-sectional and longitudinal outcomes respectively. All tests were two-tailed and $\mathrm{P}<0.05$ considered statistically significant. SPSS(Version 17.0, SPSS Inc., Chicago, IL, USA) and Prism (Version 5, GraphPad Software, San Diego, CA, USA) were used for statistical analyses.

\section{RESULTS}

A total of 101 patients who received isolated MVS at Auckland City Hospital from 2005-2012 were included in the study. Out of the 101 patients, 20 patients were part of the octogenarian group at time of surgery, and the remaining 81 in the septuagenarian group. Baseline characteristics are listed in Table 1. There were no significant differences in preoperative characteristics between the two groups apart from age (median age 82 years for octogenarians and 74 years for septuagenarians, $\mathrm{P}<0.001)$ and previous stroke $(15 \%$ in octogenarians and $1.2 \%$ septuagenarians, $\mathrm{P}=0.024)$. Significantly higher median scores were found in the octogenarians compared to the septuagenarians for two of three risk models: EuroSCORE(11.4\% and 7.0\% respectively, $\mathrm{P}=0.01)$ and STS score $(5.6 \%$ and $2.8 \%$ respectively, $\mathrm{P}=0.02)$.

Table 1. Baseline characteristics.

\begin{tabular}{|l|c|c|c|}
\hline & $\begin{array}{c}\text { Octogenarians } \\
(\mathbf{n}=\mathbf{2 0})\end{array}$ & $\begin{array}{c}\text { Septuagenarians } \\
(\mathbf{n = 8 1})\end{array}$ & P-value \\
\hline Demographics & & & \\
\hline Age (years) & $82.0(81.0-83.8)$ & $74.0(71.5-77.0)$ & $<0.001$ \\
\hline Female & $35.0 \%(7)$ & $45.7 \%(37)$ & 0.456 \\
\hline Ethnicity & & & 0.218 \\
\hline New Zealand European & $100.0 \%(20)$ & $86.4 \%(70)$ & \\
\hline Maori or Pacific & $0.0 \%(0)$ & $6.2 \%(5)$ & \\
\hline
\end{tabular}


(Table 1) contd.....

\begin{tabular}{|c|c|c|c|}
\hline & $\begin{array}{c}\text { Octogenarians } \\
(n=20)\end{array}$ & $\begin{array}{c}\text { Septuagenarians } \\
(n=81)\end{array}$ & P-value \\
\hline Other & $0.0 \%(0)$ & $7.4 \%(6)$ & \\
\hline Body mass index $\left(\mathrm{kg} / \mathrm{m}^{\wedge} 2\right)$ & $25.1(21.0-28.0)$ & $25.6(21.7-30.0)$ & 0.490 \\
\hline Body Surface Area $\left(\mathrm{m}^{\wedge} 2\right)$ & $1.77(1.55-1.91)$ & $1.79(1.66-2.04)$ & 0.201 \\
\hline \multicolumn{4}{|l|}{ Presentation } \\
\hline \multicolumn{4}{|l|}{ New York Heart Association Class } \\
\hline 1 & $5.0 \%(1)$ & $11.1 \%(9)$ & \\
\hline 2 & $45.0 \%(9)$ & $25.9 \%(21)$ & \\
\hline 3 & $25.0 \%(5)$ & $49.4 \%(40)$ & \\
\hline 4 & $25.0 \%(5)$ & $13.6 \%(11)$ & \\
\hline Unstable angina Class 4 & $0.0 \%(0)$ & $0.0 \%(0)$ & 1.000 \\
\hline Syncope & $0.0 \%(0)$ & $2.5 \%(2)$ & 1.000 \\
\hline Critical pre-operative state & $5.0 \%(1)$ & $6.2 \%(5)$ & 1.000 \\
\hline Inpatient urgent operation & $45.0 \%(9)$ & $50.6 \%(41)$ & 0.666 \\
\hline \multicolumn{4}{|l|}{ Past medical history } \\
\hline Previous cardiac surgery & $25.0 \%(5)$ & $19.8 \%(16)$ & 0.759 \\
\hline Valve surgery & $10.0 \%(2)$ & $9.9 \%(8)$ & 1.000 \\
\hline Coronary artery bypass grafting & $10.0 \%(2)$ & $6.2 \%(5)$ & 0.623 \\
\hline Congestive heart failure & $45.0 \%(9)$ & $38.3 \%(31)$ & 0.616 \\
\hline Myocardial infarction & $15.0 \%(3)$ & $12.3 \%(10)$ & 0.718 \\
\hline Recent myocardial infarction in 90 days & $5.0 \%(1)$ & $1.2 \%(1)$ & 0.358 \\
\hline Percutaneous coronary intervention & $5.0 \%(1)$ & $3.7 \%(3)$ & 0.576 \\
\hline Atrial fibrillation & $60.0 \%(12)$ & $63.0 \%(51)$ & 0.802 \\
\hline Diabetes & $0.0 \%(0)$ & $3.8 \%(3)$ & 1.000 \\
\hline Hypertension & $40.0 \%(8)$ & $45.7 \%(37)$ & 0.803 \\
\hline Hypercholesterolaemia & $40.0 \%(8)$ & $49.4 \%(40)$ & 0.618 \\
\hline Current smoker & $0.0 \%(0)$ & $1.2 \%(1)$ & 1.000 \\
\hline Smoking history & $45.0 \%(9)$ & $50.6 \%(41)$ & 0.804 \\
\hline Active infective endocarditis & $5.0 \%(1)$ & $1.2 \%(1)$ & 0.358 \\
\hline Cerebrovascular accident & $15.0 \%(3)$ & $1.2 \%(1)$ & 0.024 \\
\hline Extracardiacarteriopathy & $5.0 \%(1)$ & $4.9 \%(4)$ & 1.000 \\
\hline Chronic pulmonary disease & $15.0 \%(3)$ & $21.0 \%(17)$ & 0.756 \\
\hline Dialysis & $0.0 \%(0)$ & $0.0 \%(0)$ & 1.000 \\
\hline \multicolumn{4}{|l|}{ Investigations } \\
\hline Ejection Fraction $<50 \%$ & $10.0 \%(2)$ & $22.2 \%(18)$ & 0.348 \\
\hline Mitral regurgitation & $100.0 \%(20)$ & $95.1 \%(77)$ & 0.582 \\
\hline Mitral stenosis & $5.0 \%(1)$ & $6.2 \%(5)$ & 1.000 \\
\hline Aortic regurgitation & $5.0 \%(1)$ & $1.2 \%(1)$ & 0.358 \\
\hline Aortic stenosis & $5.0 \%(1)$ & $0.0 \%(0)$ & 0.198 \\
\hline Tricuspid regurgitation & $25.0 \%(5)$ & $22.2 \%(18)$ & 0.772 \\
\hline Pulmonary hypertension & & & 0.922 \\
\hline Moderate $(31-55 \mathrm{mmHg})$ & $55.0 \%(11)$ & $50.7 \%(38)$ & \\
\hline Severe $(>55 \mathrm{mmHg})$ & $20.0 \%(4)$ & $20.0 \%(15)$ & \\
\hline Left main artery $\geq 50 \%$ stenosis & $0.0 \%(0)$ & $1.2 \%(1)$ & 1.000 \\
\hline Main coronary vessels $\geq 50 \%$ stenosis & & & 0.405 \\
\hline 1 & $25.0 \%(5)$ & $12.3 \%(10)$ & \\
\hline 2 & $5.0 \%(1)$ & $3.7 \%(3)$ & \\
\hline 3 & $10.0 \%(2)$ & $7.4 \%(6)$ & \\
\hline Estimated glomerular filtration rate $(\mathrm{mL} / \mathrm{min})$ & $59(53-84)$ & $60(50-76)$ & 0.753 \\
\hline \multicolumn{4}{|l|}{ Risk score } \\
\hline EuroSCORE & $11.4(7.5-21.4) \%$ & $7.0(5.1-13.1) \%$ & 0.010 \\
\hline EuroSCORE II & $4.5(2.3-9.2) \%$ & $3.4(2.1-5.1) \%$ & 0.165 \\
\hline STS Score & $5.6(3.0-9.1) \%$ & $2.8(1.7-4.4) \%$ & 0.002 \\
\hline
\end{tabular}

All figures are median (lower quartile-upper quartile) or percentage (frequency). 
The operative variables and in-hospital outcomes for each group are demonstrated in Table 2. There were no differences observed for operative variables measured, with approximately half of patients having mitral repair and replacement for both groups. There were also no differences in operative mortality and all complications (stroke, renal failure, ventilation $>24$ hours, mediastinitis and return to theatre) and their composite between the two groups. Notably none of the patients died in-hospital or within 30-days in the octogenarian group, and 6 (7.4\%) died in septuagenarian group although P-value was not statistically significant at 0.596 .

Table 2. Operative variables and post-operative outcomes.

\begin{tabular}{|l|c|c|c|}
\hline & $\begin{array}{c}\text { Octogenarians } \\
(\mathbf{n = 2 0})\end{array}$ & $\begin{array}{c}\text { Septuagenarians } \\
(\mathbf{n = 8 1})\end{array}$ \\
\hline Operative variables & & & P-value \\
\hline Valve replacement & $50.0 \%(10)$ & $49.4 \%(40)$ & 1.000 \\
\hline \multicolumn{1}{|c|}{ Mechanical valve } & $80 \%(8 / 10)$ & $60.0 \%(24 / 40)$ & 0.075 \\
\hline Valve repair & $50.0 \%(10)$ & $50.6 \%(41)$ & 1.000 \\
\hline Operation time (minutes) & $178(152-248)$ & $218(170-242)$ & 0.392 \\
\hline Cardiopulmonary bypass time (minutes) & $98(84-145)$ & $118(100-146)$ & 0.248 \\
\hline Cross-clamp time (minutes) & $73(57-107)$ & $88(73-109)$ & 0.126 \\
\hline In-hospital outcomes & & & 0.596 \\
\hline Operative mortality & $0.0 \%(0)$ & $7.4 \%(6)$ & 0.786 \\
\hline Composite morbidity & $30.0 \%(6)$ & $27.2 \%(22)$ & 1.000 \\
\hline Stroke & $0.0 \%(0)$ & $2.5 \%(2)$ & 1.000 \\
\hline Renal failure & $0.0 \%(0)$ & $2.5 \%(2)$ & 1.000 \\
\hline Ventilation>24 hours & $20.0 \%(4)$ & $19.8 \%(16)$ & 0.358 \\
\hline Mediastinitis & $5.0 \%(1)$ & $1.2 \%(1)$ & 1.000 \\
\hline Return to theatre & $10.0 \%(2)$ & $9.9 \%(8)$ & 0.189 \\
\hline Operation to discharge time (days) & $8.7(8.0-12.2)$ & $8.0(6.1-10.2)$ & \\
\hline
\end{tabular}

All figures are median (lower quartile-upper quartile) or percentage (frequency).

Fig. (1) illustrates the survival during a mean follow-up of 5.1+/-2.6 years for both groups. One, three and five-year survivals were $100.0 \%, 80.0 \%$ and $70.0 \%$ for octogenarians and $91.4 \%, 86.4 \%$ and $73.8 \%$ septuagenarians. There was no statistically significant difference between the two groups $(\mathrm{P}=0.986)$.

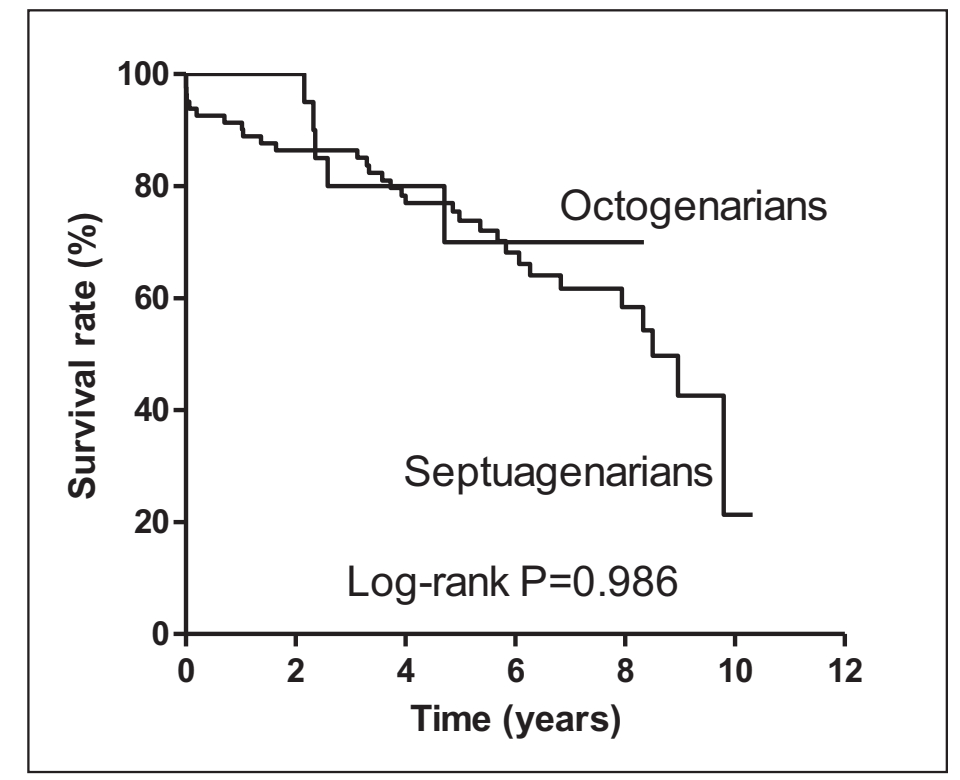

Fig. (1). Kaplan-Meier survival curves for octogenarians and septuagenarians undergoing mitral valve surgery. 
Table 3 shows predictors of post-operative mortality and complications in multivariate analysis for the study cohort. Cardiopulmonary bypass time and age were independent predictors of operative and long-term mortality respectively; history of congestive heart failure was a predictor of composite morbidity and history of previous cardiac surgery was a predictor of return to theatre.

Table 3. Multivariate analysis (for predictors $\mathbf{P}<\mathbf{0 . 1 0}$ ).

\begin{tabular}{|l|c|c|c|}
\hline Outcomes/Predictors & Ratios & $\mathbf{9 5 \%}$ confidence interval & P-value \\
\hline Operative mortality & & & \\
\hline Cardiopulmonary bypass time (per minute) & 1.02 & $1.00-1.04$ & 0.044 \\
\hline Mortality during follow-up & & & \\
\hline Age (per year) & 1.11 & $1.02-1.20$ & 0.018 \\
\hline Critical pre-operative state & 2.85 & $0.904-8.97$ & 0.074 \\
\hline Composite morbidity & & & 0.040 \\
\hline Congestive heart failure & 3.03 & $1.05-8.72$ & 0.068 \\
\hline Previous stroke & 8.87 & $0.849-92.8$ & \\
\hline Ventilation>24 hours & & & 0.063 \\
\hline Pulmonary hypertension (per category) & 2.19 & & \\
\hline Return to theatre & & $0.959-5.02$ & \\
\hline Congestive heart failure & 5.93 & & 0.053 \\
\hline Previous cardiac surgery & 11.3 & $0.975-36.0$ & 0.029 \\
\hline
\end{tabular}

All ratios are odds ratios, except hazards ratios for predictors of mortality during follow-up.

Results of the discriminant analysis for risk scores at predicting outcomes are presented in Table 4. None of the risk scores were able to predict mortality and most morbidities. However, EuroSCORE could predict renal failure (AUC 0.742, 95\% CI 0.576-0.906) and mediastinitis (EuroSCORE AUC 0.717, 95\% CI 0.598-0.837); EuroSCORE II predicted stroke (AUC $0.722,95 \% \mathrm{CI} 0.632-0.812$ ) and mediastinitis (AUC $0.818,95 \% \mathrm{CI} 0.742-0.894$ ); and STS Score predicted composite morbidity (AUC $0.649,95 \%$ CI $0.530-0.769$ ), stroke (AUC $0.742,95 \% \mathrm{CI} 0.641-0.843$ ) and mediastinitis (AUC 0.687, 95\% CI 0.512-0.86).

Table 4. Discrimination analyses for risk scores at predicting outcomes. Area under the curve (95\% confidence interval).

\begin{tabular}{|l|c|c|c|}
\hline & EuroSCORE & EuroSCORE II & STS \\
\hline Operative mortality & $0.615(0.378-0.852)$ & $0.535(0.319-0.752)$ & $0.554(0.313-0.795)$ \\
\hline Mortality during follow-up & $0.574(0.455-0.692)$ & $0.575(0.455-0.695)$ & $0.570(0.449-0.691)$ \\
\hline Composite morbidity & $0.591(0.461-0.722)$ & $0.606(0.478-0.735)$ & $0.649(0.530-0.769)$ \\
\hline Stroke & $0.591(0.489-0.693)$ & $0.722(0.632-0.812)$ & $0.742(0.641-0.843)$ \\
\hline Renal failure & $0.742(0.576-0.909)$ & $0.606(0.509-0.703)$ & $0.566(0.410-0.722)$ \\
\hline Ventilation>24 hours & $0.598(0.454-0.743)$ & $0.612(0.472-0.752)$ & $0.633(0.495-0.722)$ \\
\hline Mediastinitis & $0.717(0.598-0.837)$ & $0.818(0.742-0.894)$ & $0.687(0.512-0.862)$ \\
\hline Return to theatre & $0.484(0.275-0.693)$ & $0.494(0.285-0.703)$ & $0.543(0.379-0.707)$ \\
\hline
\end{tabular}

\section{DISCUSSION}

Mitral valve disease is the commonest form of valvular heart disease, and along with our aging population, has led to a growing demand for mitral valve intervention with many patients remaining untreated [6, 7]. This unmet clinical need is in part due to subgroups deemed at high surgical risk, and warranting the evaluation of surgery in such patients. Our study reported favourable outcomes for isolated mitral valve surgery in carefully selected elderly patients, and these findings alongside other studies in the era of percutaneous valvular interventions have many clinical implications.

Post-operative outcomes between the two age groups were not significantly different statistically, though numerically higher operative mortality in septuagenarians compared to $0 \%$ in octogenarians. Baseline characteristics were well matched except higher prevalence of previous stroke in octogenarians. Therefore the main contributor to the higher EuroSCORE and STS Score in octogenarians was predominantly the age difference. This was a similar finding to our previous study of aortic valve replacement in elderly patients [12], and perhaps reflect a more cautious and conservative approach in selecting octogenarians for cardiac surgery compared to younger counterparts [13]. However, 
this also reflects that when elderly patients are carefully assessed pre-operatively, excellent outcomes can be obtained. Furthermore, the risk of morbidities, many of which potentially have quality of life implications, should be considered and evaluated.

Another important strategy to improve outcome beyond pre-operative evaluation is the surgical technique employed. Mitral valve repair is superior to replacement in primary mitral valve disease, and this is true in studies of elderly patients also, in terms of short and long-term mortality and stroke, with comparable re-operation rates [14 - 17]. Mitral valve repair is therefore recommended whenever possible, and feasibility may be improved by operating earlier before extensive valvular destruction and/or advanced symptoms and instability develops, as well as surgeons' expertise $[4,5,18,19]$. Although we did not find mitral valve repair or replacement be independently associated with adverse outcomes, this analysis may have been limited by the power of our study.

Importantly, we found all three conventional surgical risk models were unable to discriminate operative mortality in our cohort. This is in contrast to their good performance in general isolated mitral valve surgery patients, with area under the curve of 0.67-0.89 in other studies [20 - 22]. This can largely be explained by high risk patients, and in some ways mitral valve surgery (compared to coronary and aortic valve operations) only constituting a small proportion of the derivation cohort for surgical risk scores [8 - 10]. Prediction of complications was also poor employing these scores. There is therefore the need to assess other potentially important baseline characteristics such as functional status, cognition and the ability to respond to physiological stress ie frailty; ongoing development of newer risk models incorporating these factors to specifically address the elderly and high risk subgroups; and involvement of both the Heart Team and sound clinical judgment in decision-making for intervention.

Percutaneous mitral valve intervention techniques such as Mitraclip have been recently developed, and when compared to mitral valve surgery in high risk patients have similar operative mortality rates and improvement in symptoms, lower adverse events but increased prevalence of significant residual mitral regurgitation and need for redo procedure at up to 1 year [11]. Between 1 and 4 years, survival, mitral valve dysfunction and re-intervention rates are similar [23]. Combining these results and our findings, the main benefits of Mitraclip in high risk patients are lower complication rates (except residual mitral regurgitation), and shorter hospital stay and recovery time, which has both cost and quality of life implications particularly in elderly patients. More studies are required to identify important factors which assist selection of treatment modality, the prognostic utility of existing and newly developed risk models for Mitraclip in elderly patients, as well as long-term durability such percutaneous techniques.

There are several limitations to our study. The study size was limited as a single-centre study especially for the octogenarian subgroup, but reflects the real-world experience that very few of these patients undergo mitral valve surgery. It is a retrospective observational study with inherent biases, and we were unable to obtain the numbers, characteristics, outcomes and reasons for all the patients over 70 years of age with isolated mitral valve surgery being declined. The only long-term outcome we could collect was mortality, but other outcomes such as symptoms and quality of life are also important determinants of treatment efficacy. Follow-up was limited to a mean of about 5 years, given that this was a contemporary cohort.

\section{CONCLUSION}

In conclusion, MVS remains a safe procedure with acceptable mortality and morbidities rates in selected elderlies. In our cohort octogenarians were older with higher risk scores, but didn't have excess adverse outcomes compared to septuagenarians. Further studies are required both determine what other variables beyond age and risk scores influence outcomes, and to guide selection of treatment modality for several mitral valve disease in high risk patients.

\section{CONFLICT OF INTEREST}

The authors confirm that this article content has no conflict of interest.

\section{ACKNOWLEDGEMENTS}

Declared none.

\section{REFERENCES}

[1] Stoney WS. Evolution of cardiopulmonary bypass. Circulation 2009; 119(21): 2844-53. [http://dx.doi.org/10.1161/CIRCULATIONAHA.108.830174] [PMID: 19487602] 
[2] Cohn LH. Fifty years of open-heart surgery. Circulation 2003; 107(17): 2168-70. [http://dx.doi.org/10.1161/01.CIR.0000071746.50876.E2] [PMID: 12732590]

[3] Cohn LH, Tchantchaleishvili V, Rajab TK. Evolution of the concept and practice of mitral valve repair. Ann Cardiothorac Surg 2015; 4(4): 315-21.

[PMID: 26309840]

[4] Vahanian A, Alfieri O, Andreotti F, et al. Guidelines on the management of valvular heart disease (version 2012). Eur Heart J 2012; 33(19): 2451-96. [http://dx.doi.org/10.1093/eurheartj/ehs109] [PMID: 22922415]

[5] Nishimura RA, Otto CM, Bonow RO, et al. American College Of Cardiology/American heart association task force on practice guidelines. 2014 AHA/ACC guideline for the management of patients with valvular heart disease: A report of the American College of Cardiology/American Heart Association task force on practice guidelines. Circulation 2014; 129(23): e521-643. [http://dx.doi.org/10.1161/CIR.0000000000000031] [PMID: 24589853]

[6] Nkomo VT, Gardin JM, Skelton TN, Gottdiener JS, Scott CG, Enriquez-Sarano M. Burden of valvular heart diseases: a population-based study. Lancet 2006; 368(9540): 1005-11. [http://dx.doi.org/10.1016/S0140-6736(06)69208-8] [PMID: 16980116]

[7] Nishimura RA, Vahanian A, Eleid MF, Mack MJ. Mitral valve diseasecurrent management and future challenges. Lancet 2016; 387(10025): 1324-34.

[http://dx.doi.org/10.1016/S0140-6736(16)00558-4] [PMID: 27025438]

[8] Roques F, Michel P, Goldstone AR, Nashef SA. The logistic EuroSCORE. Eur Heart J 2003; 24(9): 881-2. [http://dx.doi.org/10.1016/S0195-668X(02)00799-6] [PMID: 12727160]

[9] Nashef SA, Roques F, Sharples LD, et al. EuroSCORE II. Eur J Cardiothorac Surg 2012; 41(4): 734-44. [http://dx.doi.org/10.1093/ejcts/ezs043] [PMID: 22378855]

[10] OBrien SM, Shahian DM, Filardo G, et al. The society of thoracic surgeons 2008 cardiac surgery risk models: Part 2 isolated valve surgery. Ann Thorac Surg 2009; 88(1)(Suppl.): S23-42. [http://dx.doi.org/10.1016/j.athoracsur.2009.05.056] [PMID: 19559823]

[11] Feldman T, Foster E, Glower DD, et al. Percutaneous repair or surgery for mitral regurgitation. N Engl J Med 2011; 364(15): $1395-406$. [http://dx.doi.org/10.1056/NEJMoa1009355] [PMID: 21463154]

[12] Wang TK, Sathananthan J, Chieng N, Gamble GD, Haydock DA, Ruygrok PN. Aortic valve replacement in over 70 and over 80 -year olds: 5year cohort study. Asian Cardiovasc Thorac Ann 2014; 22(5): 526-33. [http://dx.doi.org/10.1177/0218492313497950] [PMID: 24867025]

[13] Alexander KP, Anstrom KJ, Muhlbaier LH, et al. Outcomes of cardiac surgery in patients $>$ or $=80$ years: results from the National Cardiovascular Network. J Am Coll Cardiol 2000; 35(3): 731-8. [http://dx.doi.org/10.1016/S0735-1097(99)00606-3] [PMID: 10716477]

[14] Ailawadi G, Swenson BR, Girotti ME, et al. Is mitral valve repair superior to replacement in elderly patients? Ann Thorac Surg 2008; 86(1): $77-85$.

[http://dx.doi.org/10.1016/j.athoracsur.2008.03.020] [PMID: 18573402]

[15] Daneshmand MA, Milano CA, Rankin JS, et al. Influence of patient age on procedural selection in mitral valve surgery. Ann Thorac Surg 2010; 90(5): 1479-85 [http://dx.doi.org/10.1016/j.athoracsur.2010.05.075] [PMID: 20971244]

[16] Silaschi M, Chaubey S, Aldalati O, et al. Is mitral valve repair superior to mitral valve replacement in elderly patients? Comparison of shortand long-term outcomes in a propensity-matched cohort. J Am Heart Assoc 2016; 5(8): e003605. [http://dx.doi.org/10.1161/JAHA.116.003605] [PMID: 27468927]

[17] Nardi P, Pellegrino A, Olevano C, et al. Mitral valve repair for the treatment of degenerative mitral valve disease with or without prosthetic ring annuloplasty: Long-term outcomes. J Cardiovasc Surg (Torino) 2013; 54(2): 305-12. [PMID: 23138606]

[18] Ghoreishi M, Dawood MY, Gammie JS. Mitral valve surgery in elderly patients with mitral regurgitation: Repair or replacement with tissue valve? Curr Opin Cardiol 2013; 28(2): 164-9. [http://dx.doi.org/10.1097/HCO.0b013e32835da4f8] [PMID: 23314759]

[19] Sfeir PM, Jebara VA, Ayoub CM. Mitral valve repair or replacement in elderly people. Curr Opin Anaesthesiol 2006; $19(1)$ : 82-7. [http://dx.doi.org/10.1097/01.aco.0000192771.79032.29] [PMID: 16547438]

[20] Chan V, Ahrari A, Ruel M, Elmistekawy E, Hynes M, Mesana TG. Perioperative deaths after mitral valve operations may be overestimated by contemporary risk models. Ann Thorac Surg 2014; 98(2): 605-10. [http://dx.doi.org/10.1016/j.athoracsur.2014.05.011] [PMID: 24968772]

[21] Chalmers J, Pullan M, Fabri B, et al. Validation of EuroSCORE II in a modern cohort of patients undergoing cardiac surgery. Eur J Cardiothorac Surg 2013; 43(4): 688-94.

[http://dx.doi.org/10.1093/ejcts/ezs406] [PMID: 22833541] 
[22] Di Dedda U, Pelissero G, Agnelli B, De Vincentiis C, Castelvecchio S, Ranucci M. Accuracy, calibration and clinical performance of the new EuroSCORE II risk stratification system. Eur J Cardiothorac Surg 2013; 43(1): 27-32. [http://dx.doi.org/10.1093/ejcts/ezs196] [PMID: 22822108]

[23] Mauri L, Foster E, Glower DD, et al. 4-year results of a randomized controlled trial of percutaneous repair versus surgery for mitral regurgitation. J Am Coll Cardiol 2013; 62(4): 317-28.

[http://dx.doi.org/10.1016/j.jacc.2013.04.030] [PMID: 23665364]

\section{(C) 2017 Liao et al.}

This is an open access article distributed under the terms of the Creative Commons Attribution 4.0 International Public License (CC-BY 4.0), a copy of which is available at: https://creativecommons.org/licenses/by/4.0/legalcode. This license permits unrestricted use, distribution, and reproduction in any medium, provided the original author and source are credited. 